\title{
Conservative approach to the treatment of mixed mitral valve disease
}

\author{
J.R. B E LCHER \\ The London Chest and Middlesex Hospitals
}

\begin{abstract}
Belcher, J. R. (1973). Thorax, 28, 608-612. Conservative approach to the treatment of mixed mitral valve disease. One hundred patients with mixed mitral valve disease have been treated with the 'stand-by' bypass principle. In 59 the valve was replaced; in 41 a closed transventricular valvotomy was done. The results in the two groups have been compared.

The operative mortality for valvotomy was $7 \%$; for valve replacement $20 \%$. Late death occurred in $14 \%$ after valvotomy; in $25 \%$ after replacement. 'Good' results were achieved in $49 \%$ after valvotomy; in $41 \%$ after replacement. Among the survivors $61 \%$ had 'good' results after valvotomy as against $75 \%$ after replacement. Late emboli occurred in one patient after valvotomy; in 11 after replacement. Methods for improved selection of patients for simple valvotomy are discussed.
\end{abstract}

As the long-term results of mitral valve replacement are published (Kerth, Sharma, Hill, and Gerbode, 1971; Ashton and Mulder, 1971) it becomes increasingly apparent that no effort should be spared to leave the patient his own mitral valve wherever possible. Based on a previous study (Belcher, 1966), I have adopted this policy since 1965 at The London Chest and Middlesex Hospitals, and the results of 100 cases with mixed mitral valve disease and treated with this philosophy are presented.

The conservative policy is advocated because of the conviction that a slightly inefficient mitral valve is better than any current prosthesis. The alternatives have been closed mitral valvotomy done via the transventricular route (Logan and Turner, 1959) or mitral valve replacement with a Starr-Edwards valve. Neither open valvotomy nor valvoplasty has been done in this series.

\section{MATERIAL}

Between May 1965 and May 1971, 100 consecutive patients have been operated on using the 'stand-by' principle (Litwak et al., 1965). The indication has been that the patient has had mitral valve disease or (in one case) a suspicion of myxoma. It has not been used where the diagnosis has been pure stenosis, restenosis, or even re-restenosis, nor has it been adopted when either the aortic or tricuspid valve has needed treatment. Patients with pure incompetence have not been included in this study as, in these cases, it was decided before operation that valve replacement was necessary.
All had considerable disability; in some it was severe. There were 33 men and 67 women; their average age was $50 \cdot 1$ years.

\section{PATHOLOGY}

All save one patient had mixed mitral valve disease in that the valve orifice was smaller than normal and there was mitral incompetence. The severity of these lesions varied from almost pure stenosis with a small leak to almost pure incompetence with only minor commissural fusion. Those towards the more stenotic end of the spectrum more frequently had a valvotomy, those at the other end had valve replacement.

\section{PREVIOUS OPERATIONS}

Forty-nine of the patients under consideration were from a large series who had previously had a closed mitral valvotomy. In 38 the operation under discussion was a second one, and in 11 a third, after two previous closed valvotomies.

\section{PROCEDURE}

All the patients were operated on via a left posterolateral thoracotomy as, by this route alone, it is possible to do a closed valvotomy or a valve replacement with equal facility. The decision as to which of these operations was done rested on palpation in the left atrium and pressure recordings from the left atrium and ventricle before and after a trial closed valvotomy.

The patients were followed up and none has been lost sight of. Almost every one has been seen person- 
ally within the last 12 months. The exercise tolerance, the physical signs, and the radiological changes have been assessed, particular attention being paid to those in whom simple valvotomy had proved unsuccessful.

Patients were categorized 'excellent', 'good', 'fair', and 'poor', but in order to make assessment easier, those thought to be 'excellent' or 'good' were classified as 'good'; and those who were thought to be 'fair' or 'poor' were classified as 'poor', although a number of those in the second group had some benefit from their operation. Those who initially had a closed valvotomy but subsequently required a valve replacement were classified as 'poor' or as 'late death' if they succumbed at the subsequent operation.

Identical criteria for assessment were used for the two groups, although the presence of a residual systolic murmur in those who had a valvotomy was disregarded, as all the patients in this group had some incompetence as part of the basis of the study.

\section{RESULTS}

The results are shown in Table I. The mean followup period was 35 months (69 months to 1 year); for those treated with valvotomy the mean was 42 months (64 months to 1 year); and for those with valve replacement 45 months (69 months to 1 year).

T A B LE I

RESULTS OF 100 PATIENTS IN THE SERIES

\begin{tabular}{|c|c|c|c|c|c|c|}
\hline & \multirow{2}{*}{ Total } & \multirow{2}{*}{$\begin{array}{l}\text { Operative } \\
\text { Death }\end{array}$} & \multirow{2}{*}{$\begin{array}{c}\text { Late } \\
\text { Death }\end{array}$} & \multicolumn{2}{|c|}{ Result } & \multirow{2}{*}{$\begin{array}{c}\text { Total } \\
\text { Mortality }\end{array}$} \\
\hline & & & & Good & Poor & \\
\hline $\begin{array}{l}\text { TVV } \\
\text { MVR }\end{array}$ & $\begin{array}{l}41 \\
59\end{array}$ & $12(20 \%)$ & $\begin{array}{r}6(14 \%) \\
15(25 \%)\end{array}$ & $\begin{array}{l}20(49 \%) \\
24(41 \%)\end{array}$ & $\begin{array}{r}12(28 \%) \\
8(13 \%)\end{array}$ & $\begin{array}{c}9(22 \%) \\
27(45 \%)\end{array}$ \\
\hline
\end{tabular}

TVV $=$ transventricular valvotomy;

MVR=mitral valve replacement.

Operative death was defined as death within three weeks of surgery.

These figures show that $\mathbf{3 2}$ of those who had a closed operation are still alive $(78 \%)$ and that 20 were thought to have a good result ( $61 \%$ of the survivors). On the other hand, only 32 of those whose valves were replaced were still alive (59\%) but 24 of these were thought to have 'good' results $(75 \%)$.

These figures make no allowance for the incidence of late non-fatal complications. There was only one among the 'valvotomy' group, an immediate postoperative embolus leading to a 'poor' result in a patient whose haemodynamics were satisfactory. There were 11 late complications among the patients whose valves were replaced $(33 \%)$, and only 17 of the original 59 had an entirely satisfactory result $(29 \%)$. There were 10 late emboli (5 multiple) and one late infection. In this non-fatal group the emboli were minor except in two patients who were haemodynamically satisfactory but gravely disabled with a hemiplegia. Thus from these figures it seems that if it is possible not to replace the mitral valve, there is at least twice the chance of long-term survival, at least three times the chance of surviving the immediate postoperative period, a much greater chance of avoiding non-lethal late complications, but a $14 \%$ less chance of a good result among those who survived the operation.

POOR RESULTS OF CLOSED VALVOTOMY The patients in whom closed valvotomy gave unsatisfactory results in this series have been studied in the hope that the incidence of this error could be reduced. In all there were 18 such cases and the probable reasons for the failures are given in Table II.

\section{T A B LE I I}

REASONS FOR FAILURE OF CLOSED VALVOTOMY

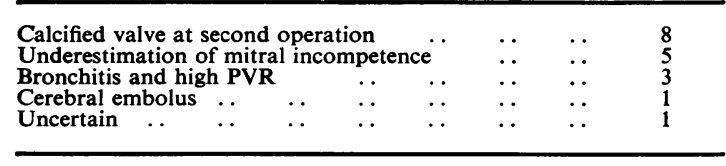

A simultaneous study (Smith and Belcher, 1970) established that the results of closed valvotomy in patients with heavily calcified valves requiring second operations were unacceptable and that valve replacement should have been done. The eight patients reported here formed part of this other series and should not have had a closed valvotomy.

In the five patients with underestimation of mitral incompetence there was mixed disease with neither the stenosis nor the incompetence dominant. It seems likely that the incompetence was increased by the valvotomy and that this was not appreciated.

Of these 18 patients, in whom the conservative policy failed, including the six 'late deaths', four died at or after subsequent valve replacement of their calcified valves. Thus with the elimination of this group in the future the proportion of 'late deaths' after valvotomy should be considerably diminished.

GOOD RESULTS FOLLOWING TRANSVENTRICULAR VALVOTOMY Good results were obtained in 20 patients who had simple closed valvotomy, and it is with the correct selection of these that this 
paper is chiefly concerned. The avoidance of valve replacement in a quarter of the patients with mixed mitral valve disease was, as the results show, a worth-while achievement.

None of the 20 patients had grade III mitral incompetence, but six were thought to have had grade II incompetence with little stenosis, seven were thought to have had truly mixed disease with both stenosis and incompetence contributing to the disability, and only seven were thought to have dominant or pure mitral stenosis. Five of those with dominant stenosis had calcification of the valve, but this complication was present in only two of the remaining 13 cases.

Twelve of this group with good results had residual incompetence after the valvotomy, which was classified as grade II; in the remaining nine it was trivial but readily palpable in the beating heart.

These results emphasize the fact that the presence of moderate mitral incompetence after a valvotomy, or of calcification, are not necessarily indications for valve replacement.

POOR RESULTS FOLLOWING VALVE REPLACEMENT The survivors of valve replacement do not all have satisfactory results. In this series there have been $15(25 \%)$ late deaths and nine poor results. Thus, in contrast to the results following valvotomy, unsatisfactory results have led to death rather than disability.

The probable causes of the late deaths are shown in Table III.

\section{T A B LE I I I}

CAUSES OF LATE DEATH AFTER VALVE REPLACEMENT

\begin{tabular}{llll|l}
\hline Infection and septicaemia & $\ldots$ & $\ldots$ & 5 (average survival 12/12) \\
Sudden death & $\ldots$ & $\ldots$ & $\ldots$ & 4 (average survival 41/12) \\
Congestive failure & $\ldots$ & $\ldots$ & $\ldots$ & 3 (average survival 23/12) \\
Valve leakage & $\ldots$ & $\ldots$ & $\ldots$ & 3 (average survival 32/12) \\
\hline
\end{tabular}

As patients who had valves replaced were thought to have sufficient incompetence to justify this, it is important to decide whether replacement was the cause of the late deaths. As death from late infection after closed mitral valvotomy is rare, it seems probable that the five patients who died from this cause succumbed because of the presence of the.prosthesis rather than because of pre-existing incompetence. Of the three who died suddenly, one had mechanical failure of the prosthesis, one died of thrombus formation around the ring, and the cause of the third and fourth is unknown although probably embolic. Three patients died because of valve leakage. Thus in $11 \frac{\bar{\sigma}}{\bar{c}}$ cases the existence of the incompetence was not $\overparen{\Omega}$ directly related to the late death. It is possible that the three patients who died from cardiac failure ${ }^{\text {s }}$ did so because of long-standing left ventricular. strain, but it seems more likely that it was the $\vec{\overrightarrow{ }}$ presence of the foreign body and not the severity of the incompetence that was mainly responsible $\overrightarrow{\vec{x}}$ for this alarmingly high incidence of late fatalities.

Seven of the patients died within one year of leaving hospital, but the remaining eight deaths occurred after periods of up to 52 months. Other $\infty$ authors (Kerth et al., 1971) record a similar ex-o perience, and although these deaths appear to become less common after five years (Ashton andes Mulder, 1971 ; Rees et al., 1970), there are still $\mathbb{O}$ many patients in this series who had their operation well within this period and it is thus probable that the incidence of late death directly attributable to $\stackrel{\mathbb{}}{-}$ the operation will increase.

\section{DISCUSSION}

No treatment for mixed mitral valve disease is perfect and the excellent results of open or closed市 surgery in mitral stenosis cannot be matched when there is an element of mitral incompetence.

The arguments about what should be done for these difficult patients centres around two pro-跨 blems; what results are acceptable in those patients in whom a valvotomy is done, and, secondly, to what extent is the risk of valve replacement justifiable? Some of the published results of this operation are shown in Table IV 3 and these figures emphasize the gravity of the decision to replace the patient's mitral valve.

The operative mortality of transventricular ${ }_{0}$

\section{T A B L E I V}

EARLY AND LATE MORTALITY OF MITRAL VALVE REPLACEMENT

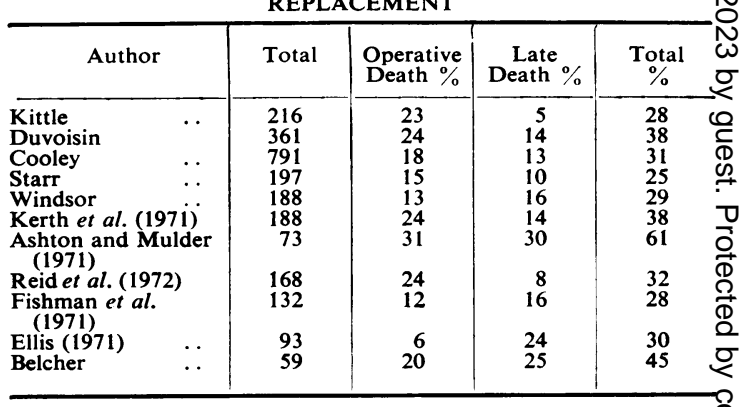

The figures quoted are largely derived from Kerth et al. (1971) 
valvotomy now stands at $2.5 \%$ and it was $7 \%$ in this series. Few series of mitral valve replacement, including almost half with second or third operations, can approach this figure (Wisheart, Ross, and Ross, 1972). Thus the conservative approach is justifiable on grounds of lower operative mortality (Table V).

Although half of the late deaths in this series and in others (Kerth et al., 1971) occurred within a year of operation, others occurred much later and, with few exceptions, those with the lowest late mortality tended to be those with the shorter periods of follow-up.

T A B L E V

OPERATIVE MORTALITY

\begin{tabular}{|c|c|c|c|c|c|c|}
\hline & \multicolumn{2}{|c|}{ 1st Operation } & \multicolumn{2}{|c|}{ 2nd Operation } & \multicolumn{2}{|c|}{ 3rd Operation } \\
\hline & Total & $\begin{array}{l}\text { Operative } \\
\text { Mortality }\end{array}$ & Total & $\begin{array}{l}\text { Operative } \\
\text { Mortality }\end{array}$ & Total & $\begin{array}{l}\text { Operative } \\
\text { Mortality }\end{array}$ \\
\hline $\begin{array}{ll}\text { TVV } & \cdots \\
\text { MVR } & \cdots\end{array}$ & $\begin{array}{l}18 \\
33\end{array}$ & $\begin{array}{l}1(6 \%) \\
3(9 \%)\end{array}$ & $\begin{array}{l}17 \\
21\end{array}$ & $\begin{array}{l}1(6 \%) \\
6(29 \%)\end{array}$ & $\begin{array}{l}6 \\
5\end{array}$ & $\begin{array}{l}1(16 \%) \\
3(60 \%)\end{array}$ \\
\hline Total & 51 & $4(8 \%)$ & 38 & $7(17 \%)$ & 11 & $4(36 \%)$ \\
\hline
\end{tabular}

On the other hand, although there were six late deaths after valvotomy in this series. four of these deaths occurred at subsequent valve replacement which was proved necessary as the judgement to leave the valve in situ was proved incorrect. With the reduction of this error based on lessons learnt during this study, it should be possible to reduce the incidence of late death after valvotomy still further to considerably less than half that after valve replacement. Thus on this second count also the attempt at conservation of the valve seems justified.

Consideration must be given to the state of the survivors. There are 32 patients from each group. Seventy-five per cent of those who had a mitral valve replacement as against $61 \%$ of those who had a closed valvotomy had good results. Thus, only on this criterion are the results of replacement better.

No patient reported here had an open valvotomy. The policy was not based on the belief that closed valvotomy was a better operation, but that the disadvantage of open valvotomy was not that of operative mortality but that the valve might be unnecessarily replaced.

Secondly, it was thought that the assessment of the residual incompetence was much easier after closed valvotomy, and that methods employed while the atrium was still open might also lead to the unnecessary replacement of mildly incompetent valves.

Because of the anxiety not to replace valves, simple valvotomy was done on 12 occasions where, in the light of subsequent events, it would clearly have been better if the valves had been replaced. This error should thus be eliminated in future cases. In four patients the severity of the residual incompetence was underestimated. In three of them it had been increased by the valvotomy and the torn valves subsequently had to be replaced.

In every patient in this series the approach was made via a left posterolateral incision. This approach was used for all the second and even third operations, each of which had previously been done through the same incision. Although the operative mortality was higher in the second operations $(17 \%)$ than in the first $(8 \%)$, and was very much higher in the third (36\%) (Table V), it was thought that none of the operative deaths was due to the reopening of the chest and the pericardium via the old route.

The left-sided approach was used because only by this method is the digital examination of the mitral valve in the beating heart really satisfactory, and only by this route is closed valvotomy easy. Many methods have been used to assess the severity of mitral incompetence both before and after open and closed valvotomy, but, despite some of the errors reported here, palpation of the regurgitant jet in a heart producing a satisfactory blood pressure still remains the most reliable. It is for this reason that the left-sided approach is essential if the principle of the 'stand-by' bypass is to be used.

If the methods of selection for the closed operation which have been derived from this study had been used, only 30 of the 100 would have had this done. Of these, $70 \%$ would have had a 'good' result. There would have been one operative death and one late death. It can never be known how many had their valves replaced unnecessarily, but it is thought that there would have been few among the 59 patients presented here. Thirty per cent of patients with mixed mitral valve disease is a substantial proportion, and the number of satisfactory results which can be achieved in this group suggests that the effort to conserve the valve recommended here is more than justifiable. The recommendation made for closed valvotomy may still prove to be the most effective way of giving acceptable results in some patients with mixed mitral valve disease.

My thanks are due to my cardiological colleagues at The London Chest and the Middlesex Hospitals for their share in the care of these patients, and particularly to Dr. M. Honey for his help in the assessment of them. 


\section{REFERENCES}

Ashton, S. J., and Mulder, D. G. (1971). Cardiac valve replacement; a seven year follow-up. Journal of Thoracic and Cardiovascular Surgery, 61, 547.

Belcher, J. R. (1966). What are the indications for mitral valve replacement? British Medical Journal, 2, 1486.

Ellis, F. H. (1971). Discussion of Fishman et al. Journal of Thoracic and Cardiovascular Surgery, 62, 355.

Fishman, N. H., Edmunds, L. H., Hutchinson, J. C., and Roe, B. B. (1971). Five year experience with the SmeloffCutter mitral prosthesis. Journal of Thoracic and Cardiovascular Surgery, 62, 345.

Kerth, W. J., Sharma, G., Hill, J. D., and Gerbode, F. (1971). A comparison of the late results of replacement and reconstructive procedures for acquired mitral valve disease. Journal of Thoracic and Cardiovascular Surgery, 61, 14.
Litwak, R. S., Gadboys, H. L., Baron, M. G., Lev, R., and Wallace, H. W. (1965). Elective open heart surgery in mitral stenosis; experience with a stand-by pump oxygenator. American Journal of Cardiology, 16, 206.

Logan, A., and Turner, R. (1959). Surgical treatment of mitral stenosis with particular reference to the transventricular approach. Lancet, 2, 874.

Rees, J. R., Miscall, B. G., Holswade, G. R., Castenada, A., and Lillehei, J. (1970). Late results of mitral valve replacement. Surgery, 67, 141.

Reid, J. M., Barclay, R. S., and Stevenson, J. G. (1972). Long-term follow-up of mitral valve replacement with Starr-Edwards valves. British Heart Journal, 34, 129.

Smith, G. H., and Belcher, J. R. (1970). Valvotomy in calcific mitral stenosis. British Heart Journal, 32, 198.

Wisheart, J. D., Ross, D. N., and Ross, J. K. (1972). A review of the effect of previous operations on the results of open-heart surgery. Thorax, 27, 137. 